\title{
Inhaltsverzeichnis
}

Vorwort

vii

I Beziehungen im Wirtschaftsleben $\quad 1$

1 Sozialkapital, Vertrauen und Kooperation 3

Norman Braun

2 Netzwerke im Arbeitsmarkt

Patrick Riordan und Fabian Kratz

3 Status, Positionswettbewerbe und Signale

Tobias Wolbring

\section{Institutionen und Wirtschaft}

4 Online-Transaktionen und Auktionen

Roger Berger und Julia Zimmermann

5 Wirtschaft und Religion

Eva Negele

6 Märkte und Prognosen

Jochen Groß

\section{Konsumentenverhalten}

7 Konsum, Kaufverhalten und Konformität

Norman Braun und Marc Keuschnigg

8 Sucht, Gewohnheit und Tradition

Roger Berger und Thomas Wimmer

$9 \quad$ Stars und ihre Entstehung

Marc Keuschnigg 


\section{Wohlstand und Ungleichheit}

10 Nationale und internationale Einkommensverteilung

Marc Keuschnigg und Jochen Groß

11 Körpermerkmale und Lohnbildung

Christiane Bozoyan und Tobias Wolbring

12 Einkommen und Lebenszufriedenheit

Marc Keuschnigg, Eva Negele und Tobias Wolbring 